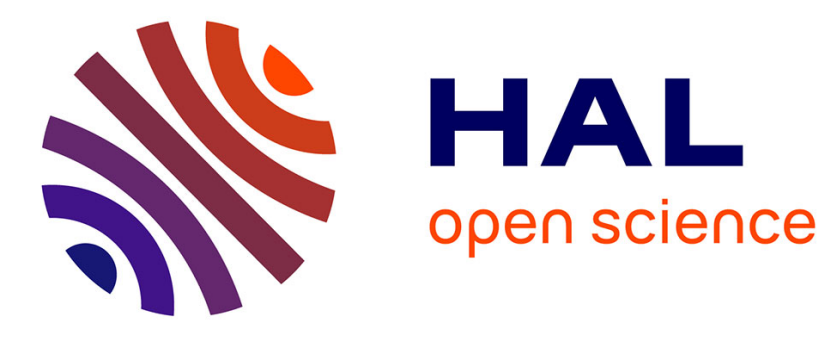

\title{
Humans in the enterprise interoperability ecosystem
}

Fernando Luis-Ferreira, Hervé Panetto, Ricardo Jardim-Gonçalves

\section{To cite this version:}

Fernando Luis-Ferreira, Hervé Panetto, Ricardo Jardim-Gonçalves. Humans in the enterprise interoperability ecosystem. 6th International IFIP Working Conference on Enterprise Interoperability (IWEI), May 2015, Nîmes, France. pp.92-98, 10.1007/978-3-662-47157-9_9 . hal-01140396

\section{HAL Id: hal-01140396 \\ https://hal.science/hal-01140396}

Submitted on 8 Apr 2015

HAL is a multi-disciplinary open access archive for the deposit and dissemination of scientific research documents, whether they are published or not. The documents may come from teaching and research institutions in France or abroad, or from public or private research centers.
L'archive ouverte pluridisciplinaire HAL, est destinée au dépôt et à la diffusion de documents scientifiques de niveau recherche, publiés ou non, émanant des établissements d'enseignement et de recherche français ou étrangers, des laboratoires publics ou privés.

\section{(c)(1)}

Distributed under a Creative Commons Attribution| 4.0 International License 


\title{
Humans in the Enterprise Interoperability Ecosystem
}

\author{
Fernando Luis-Ferreira $^{1,2}$, Hervé Panetto ${ }^{3,4}$, Ricardo Jardim-Goncalves ${ }^{1,2}$ \\ ${ }^{1}$ Departamento de Engenharia Electrotécnica, Faculdade de Ciências e Tecnologia, FCT, \\ Universidade Nova de Lisboa, 2829-516 Caparica, Portugal \\ ${ }^{2}$ Centre of Technology and Systems, CTS, UNINOVA, 2829-516 Caparica, Portugal \\ ${ }^{3}$ CNRS, CRAN UMR 7039, France \\ ${ }^{4}$ Université de Lorraine, CRAN UMR 7039, B.P. 70239 F-54506 Vandœuvre-lès-Nancy, \\ France \\ flf@uninova.pt, herve.panetto@univ-lorraine.fr, rg@uninova.pt
}

\begin{abstract}
Enterprises are complex live organisms of humans and networked machines including diverse types of computational devices. Enterprise interoperability promotes the interaction between companies based in the interoperability between such companies and between devices and services inside the company. Knowledge management is another important aspect that is extensively observed in the dynamic enterprise ecosystem. It is understandable that studies make different types of assessment for machines and people. In this sense we can ask on the interest of studying humans along machines in the chain of collaboration inside the Enterprise Interoperability Ecosystem. What we propose is to establish measures that promote interoperability between computational devices and humans, at the same time that we can promote interoperability between humans using computational devices to interact between each other.
\end{abstract}

Keywords: Enterprise Interoperability, Emotions, Human Computer Interaction

\section{Introduction}

Today enterprise's competitiveness is, to a large extent, determined by its ability to seamlessly interoperate with other companies. The advantage of one enterprise over another stems from the way it manages its process of innovation. Enterprise Interoperability (EI) has therefore become an important area of research to ensure the competitiveness and growth of European enterprises [1]. The activities within an enterprise are complex as companies manufacture a variety of products using different production methods to satisfy different customer demands. An enterprise model is defined as "the art of externalising enterprise knowledge, which adds value to the enterprise or needs to be shared"'[2]. The word interoperability has many different 
uses. The term interoperability is increasingly used in enterprise engineering and its related standardization activities [3]. While interoperable systems can function independently, an integrated system loses significant functionality if the flow of services is interrupted. An integrated family of systems must, by necessity, be interoperable, but interoperable systems need not be integrated. Integration also deals with organisational issues, in possibly a less formalised manner due to dealing with people, but integration is much more difficult to solve, while interoperability is more of a technical issue. Compatibility is something less than interoperability. It means that systems/units do not interfere with each other's functioning. But it does not imply the ability to exchange services. Interoperable systems are by necessity compatible, but the converse is not necessarily true. To realize the power of networking through robust information exchange, one must go beyond compatibility. [4]. In what regards to the human aspect we should not expect that difficulties with one person could interfere to the whole network and the knowledge exchange process within the enterprise. By knowledge we can consider the Individual Knowledge that can be found in the hands of an individual worker who serves as a fundamental unit in the process of knowledge creation, storage, and use within the enterprise. Many times this knowledge is tacit and therefore not well documented. Group knowledge is more powerful than the sum of the knowledge acquired by an individual. This knowledge can be both formal and informal and is frequently intangible but is one of the most important knowledge assets within a company. The organization, in turn, serves as a storehouse of knowledge with its own peculiar structure and divisions of functions, with multiple processes and activities to aid in the search for knowledge [5]. The present research paper departs from the analysis made in this section on the enterprise environment with a focus on the goal of pursuing Interoperability. Then in section II an overview is made on the emotions as distinguishing characteristic of the humans to be attained for the improvement of interactions both Human to Human $(\mathrm{H} 2 \mathrm{H})$ and Human computer Interaction HCI. In section III an experiment is proposed with the objectives of allowing the emotional assessment and the preparation of a strategy for performing emotional assessment within enterprise environment. In section IV results are analysed and discussed leading to conclusions in section $\mathrm{V}$. The main goal of this research work is to develop tools that, in a less-obstructive manner, allow the improvement and valuation on the role of humans in the Enterprise Interoperability Ecosystem.

\section{Mediated Human to Human Interaction and Human Computer Interaction}

The most distinguishing characteristic of humans, apart from the body, is the fact that humans feel emotions. Alan Turing back in 1950, questioned if a machine can think and for that he elaborated a test that is still in use and that could evaluate if machines can think [6]. At the same time, Jefferson was saying that "Not until a machine can write a sonnet or compose a concerto because of thoughts and emotions felt, and not by the chance fall of symbols, could we agree that machine equals brain that is, not 
only write it but know that it had written it. No mechanism could feel (and not merely artificially signal, an easy contrivance) pleasure at its successes, grief when its valves fuse, be warmed by flattery, be made miserable by its mistakes, be charmed by sex, be angry or depressed when it cannot get what it wants" what has become known as Jefferson's Oration [7]. Machines can fake the appearance of an emotion quite well, without having any feelings similar to those we would have: They can separate expression from feeling. With a machine it is easy to see how emotion expression does not imply "having" the underlying feeling [8]. As emotions play an important role in our life it is important to consider their role in human computer interaction (HCI). Affective computing is a research area developed by Rosalind Picard since the decade of ninety that addresses affective aspects in HCI. In her definition, affective computing is computing that relates to, arises from, or influences emotions [9]. In a broad sense it means, for one side, how emotions influence our behaviour in interacting with computational devices and, on the other side, how that interaction influences our emotions. In affective computing, we can separately examine functions that are not so easily separated in humans which enables a computational handle of affect related measurements [10]. Several measurements can be performed, integrating data acquired from physical environment which will increases the factor for unreliability to the overall system because of the unpredictable behaviours of the physical world [11]. Thus if we want to assess a person's emotional cues, it is necessary to develop a methodology that enables the evaluation of physiological information and correlate that information with known emotional states so that, later, becomes possible to infer emotional states from such measurements. Such measurements type of assessments is missing in what regards enterprise oriented studies as they have been made mostly for psychological studies [12] [13]. In order to be used in the enterprise ecosystem, such measurements should be the less invasive and less disturbing of daily activity as possible. The objective would be, to monitor how interaction with computational environment affects humans' emotional states and how the interaction of humans by means of using computational channels can be evaluated and mediated if needed. Envisaging this non-disturbing approach, measurement of heartbeat seems to be an interesting option, from the ergonomic point of view, as today there are many devices on the market that can be used for fitness and are used like a normal watch (e.g. Nike+ Fuelband ${ }^{1}$, Fitbit $^{2}$, Jawbone ${ }^{3}$ ).

It is also relevant to notice that emotional states can bias judgement and can alter perceptions. Emotions often seem to overpower us and to influence our judgements in profound ways. Our decisions and our actions when we feel angry or frightened or enthusiastic appear not to agree with the dictates of reason and prudence [14]. According to Saks and Johns, there are 3 factors that can influence the perceptions: experience, motivational state and, finally, emotional state [15]. Emotional states can diminish workers judgment and diminish conscientious decision capacity; in some cases it can also put them at risk. Finally, assessing emotional states can be a most

\footnotetext{
${ }^{1} \mathrm{http}: / /$ www.nike.com/us/en_us/c/nikeplus-fuelband

${ }^{2} \mathrm{http} / / /$ www.fitbit.com/

${ }^{3} \mathrm{https}$ ://jawbone.com/up
} 
relevant step for business as Nobel prize Daniel Kahneman stated, the study of peoples well-being can have a profound impact on economy [16]. In the next sections we pursue the goal of knowing more about a person's emotional state.

\section{Design experiment on emotional assessment}

The observations presented in previous sections led to the need of obtaining physiological information about a person, which could lead us to establish possible inferences about that person's emotional states. A setup to perform physiological measurements was prepared with selected laboratory equipment. A group of 24 individuals where randomly chosen to perform an experience that was meant to provide clues on assessment of human emotional states from physiological readings. The result would introduce Human Emotions as a new variable in the enterprise interoperability ecosystem. The process of inclusion is based on considering humans beyond a simplified view of knowledge managers, by valuating their nature of emotional beings. The physiological responses were based on heart rate indicators collected during visual stimulus presentation. The pictures were classified in three different categories (animals, humans and food pictures) that were organized for each of the stimulus in positive, neutral and negative, according to the scores provided by Lang et al in their Manual for the IAPS (International Affective Picture System) [17].

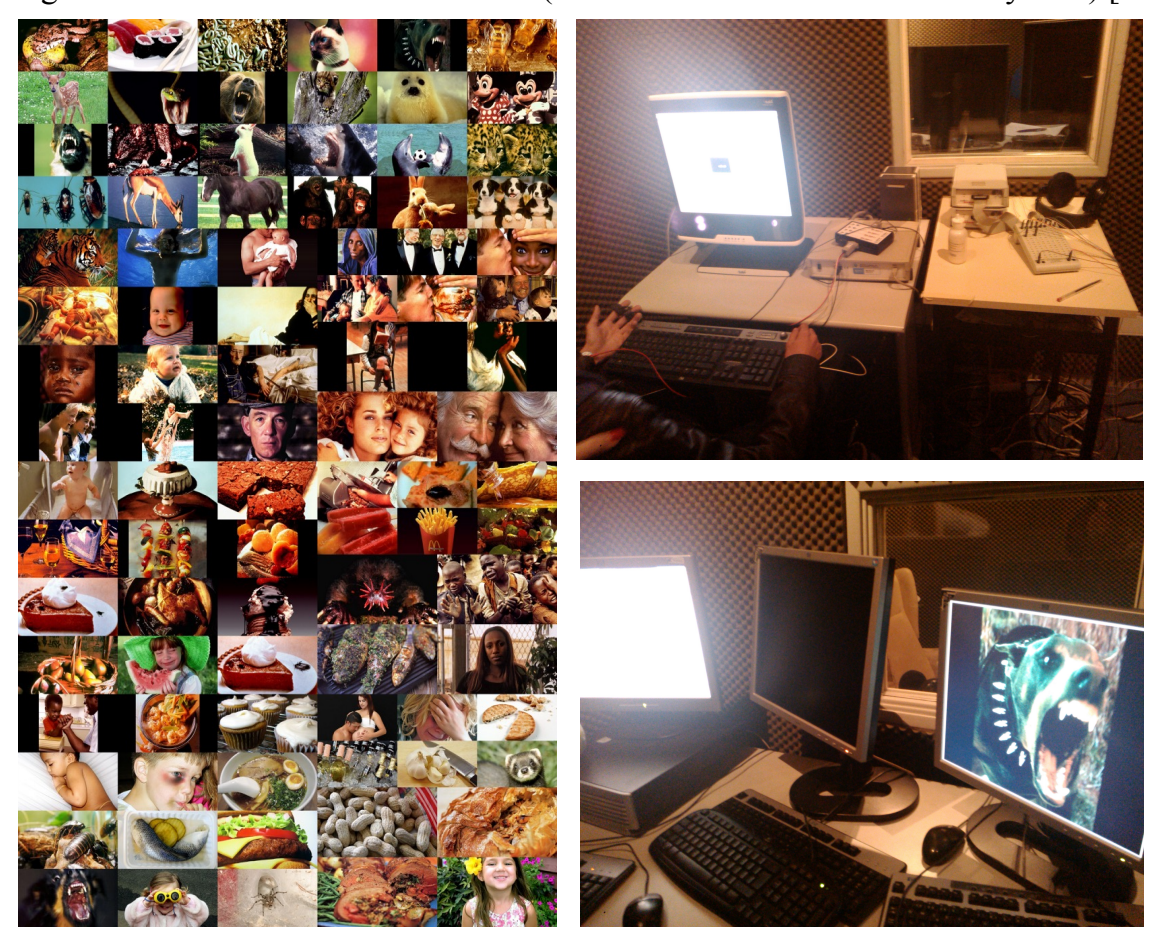

Figure 1 - Selection of images from the IAPS database (left), experimental setup (right) 
The results were collected in samples for each intervenient and we have performed an ANOVA with repeated measures with two with-subjects factors: the stimulus category with 3 levels (animals vs. humans vs. food) and the valence of these stimuli also with 3 levels (positive vs. neutral vs. negative). The main effects of each factor were analysed further using multiple comparisons with Bonferroni comparisons and the interaction effects between factors with simple main effects also with Bonferroni correction given the small sample size. The ANOVA is a F-test based on the F probability distribution. The F is estimated according to the Sum of Squares (SS) between groups dividing by the SS within groups.

\section{Results and Discussion}

The collected results were analysed taking in account data from self-assessment and physiological readings.

The results showed significant associations between the physiological and the SAM (Self Assessment Manikin) assessments for valence, activation and dominance. The correlations between these variables were significant for an alpha level of 0.05 and the Pearson $r$ coefficient ranged between 0.41 and 0.63 for the significant correlations. The most reliable indicator of the subjective assessments through the SAM scales, for several measurements performed, for the heart rate that was moderately correlated with the subjective arousal $(\mathrm{r}=.41 ; \mathrm{p}<0.05)$, as seen in Figure 2 .

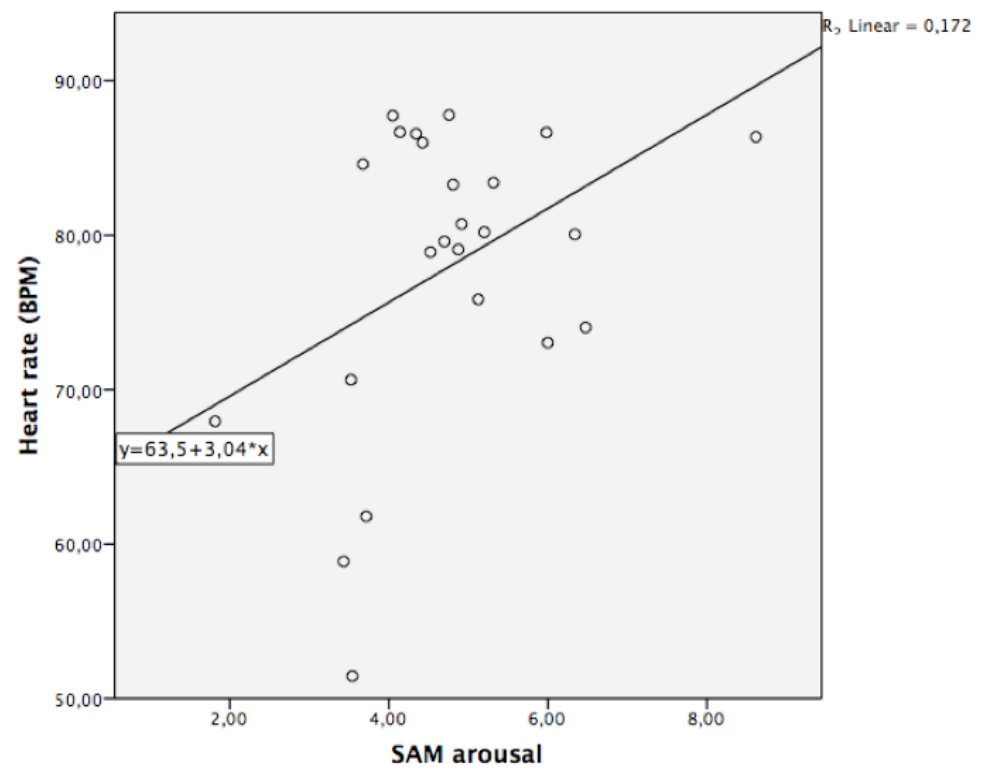

Figure 2 - SAM Activation related with Heart rate 
The correlation obtained denotes an interesting adhesion from the expressed selfassessment and the physiological measurements for heartbeat.

The dispersed values in the graph are most probably due to persons that, even without notice, they were most affected by the images. On the other side there should be individuals that think that pictures are impressing, their body didn't react in the same way. Those persons are probably calmer then they think. The measurements were made with a set of images within those three categories; it is possible that other images, like those related to sexual content, could produce other effects. Those images use to be relevant in such tests, however in about two decades the patterns of beauty or disgust change as the society change in time with new trends and new contexts, and that is the age of the IAPS picture set.

In the work performed the objective was not to determine if a person is happy, sad, with fear or in euphoria. By the contrary the objective was to analyse if with such an approach it is possible to predict, or verify, the degree of interoperability between persons in the sense that they share the same physiological manifestation. Also the protection of workers, especially for those who require most concentration (e.g. air traffic controllers) or those who may put a person at risk (e.g. using dangerous cutting or drilling tools) can be monitored and scheduled in shifts according to the results from measurements presented in this paper. It is also convenient (or mandatory) to ensure privacy of the workers. That could be achieved by a policy of only issuing warnings to the worker about measurements outside established parameters and in that case recommending a pause or some exercise. Only dangerous or risky parameters would be issued to supervisors or to the human resources department or, in extreme cases, asking for medical assistance.

The continuous update of the working model deployed in this setup can ensure the validity and adequacy of each work for each individual, according to specific environmental conditions, and which workers will better cooperate within specific tasks in the enterprise environment.

\section{Conclusions and Future Work}

The results obtained show a promising path towards emotional assessment based on physiological readings. The results show that physiological measurements are not detached from the indications given by a person's expression. Interoperability within the company can benefit by the inferences obtained about people's emotions. Workers with high variations should be spared and should not be assigned to dangerous or sensitive tasks. Emotional indicators could also give notice about the proper moment to perform a certain task within the enterprise or about the best time for performing a negotiation. Would be interesting to evaluate the result of a negotiation after the assessment to be performed. In future work would be interesting to evaluate the interoperability between people while performing a negotiation. Another interesting feature would be to perform the measurements while people are interacting with computers. Would be interesting to verify if when a person has an emotional change, interaction with computers would be affected. Future work should advance in the 
direction of the measurements to be performed with available fitness devices as stated before. The unnoticed use of devices would allow it to be used seamlessly within the enterprise thus supporting new applications and new strategies to promote people's interoperability between themselves and towards interaction with machines. Also future work should include other types of measurements that did not fit in the scope of this paper but that can be coupled with the presented measurements in order to obtain more rigorous correspondences between physiology and emotional assessment.

\section{Acknowledgements}

The research leading to these results has received funding from the EC H2020 Program under grant agreement AQUASMART N 644715 and EC 7th Framework Programme under grant agreement FITMAN No 604674 (http://www.fitman-fi.eu)

\section{References}

1. Charalabidis, Y., Gionis, G., Hermann, K.M., Martinez, C.: Enterprise Interoperability Research Roadmap. Eur. Comm. (2008).

2. Vernadat, F.: UEML: Towards a unified enterprise modelling language. Int. J. Prod. Res. 40, 4309-4321Vernadat, F. (2002). UEML: Towards a unif (2002).

3. Chen, D., Vernadat, F.: Enterprise interoperability: A standards view. Kosanke, R. Jochem, JG Nell, Bas (Eds.), Enterp. Inter-and IntraOrganizational Integr. Bost. Kluwer. (2003).

4. Panetto, H.: Towards a classification framework for interoperability of enterprise applications. Int. J. Comput. Integr. Manuf. 20, 727-740 (2007).

5. Whitman, L.E., Panetto, H.: The missing link: Culture and language barriers to interoperability. Annu. Rev. Control. 30, 233-241 (2006).

6. Turing, A.M.: Computing Machinery and Intelligence. Mind. 59, pp. 433-460 (1950).

7. JEFFERSON, G.: The mind of mechanical man. Br. Med. J. 1, 1105-10 (1949).

8. Picard, R.W.: Affective computing: challenges. Int. J. Hum. Comput. Stud. 59, 55-64 (2003).

9. $\quad$ Picard, R.W.: Affective Computing. (1997).

10. López, J.M., Gil, R., García, R., Cearreta, I., Ga-, N.: Towards an ontology for describing emotions. 1-10.

11. Ghimire, S., Luís-Ferreira, F., Jardim-Goncalves, R.: Towards Selfevolutionary Cyber Physical Systems. Advances in Transdisciplinary Engineering. pp. 547-554 (2014).

12. Mikels, J.A., Fredrickson, B.L., Larkin, G.R., Lindberg, C.M., Maglio, S.J., Reuter-Lorenz, P.A.: Emotional category data on images from the International Affective Picture System. Behav. Res. Methods. 37, 626-30 (2005).

13. Machajdik, J., Hanbury, A.: Affective image classification using features inspired by psychology and art theory. Proceedings of the international 
conference on Multimedia - MM '10. p. 83. ACM Press, New York, New York, USA (2010).

14. Handbook of Organizational Learning and Knowledge Management. John Wiley \& Sons (2011).

15. Alan, S., Gary, J.: Perception, Attribution, and Judgment of Others. Organ. Behav. Underst. Manag. Life Work. 7, (2011).

16. Kahneman, D., Krueger, A.B.: Developments in the Measurement of Subjective Well-Being. J. Econ. Perspect. 20, 3-24 (2006).

17. Lang, P.J., Bradley, M.M., Cuthbert, B.N.: International affective picture system (IAPS): Technical manual and affective ratings, (1999). 